\title{
Invited Review: Crossbreeding in Dairy Cattle: A Danish Perspective
}

\author{
M. K. Sørensen, ${ }^{*} \dagger^{1}$ E. Norberg, ${ }^{*}$ J. Pedersen, $\dagger$ and L. G. Christensenł \\ *Department of Genetics and Biotechnology, Faculty of Agricultural Sciences, Aarhus University, Research Centre Foulum, PO Box 50, DK-8830, \\ Denmark \\ †Danish Agricultural Advisory Service, Udkaersvej 15, Skejby, 8200 Aarhus N, Denmark \\ ‡Faculty of Life Sciences, Copenhagen University, Bülowsvej 17, 1870 Frederiksberg C, Denmark
}

\section{ABSTRACT}

The value of crossbreeding in livestock species has been known for a long time; it has been used heavily within beef cattle, pig, and poultry production systems for several decades. This has not been the case for dairy production but lately there has been increased interest in crossbreeding dairy breeds. This review focuses on the practical and theoretical background of crossbreeding and describes the gain to be expected using systematic crossbreeding in dairy production. In Denmark, 24\% of dairy farmers would consider starting crossbreeding programs within their herd. Evidence for the value of crossbreeding is documented with special emphasis on results from a Danish crossbreeding experiment. This experiment included 1,680 cows from 3 breeds and their crosses. In general, at least $10 \%$ heterosis can be expected for total merit, mainly due to increased longevity and improvement of functional traits. A minor part of heterosis for total merit is due to heterosis for production traits. For production, there is evidence of recombination loss using continued crossbreeding programs, which does not seem to be the case for longevity and total merit. However, recombination loss should be investigated more carefully as crossbreeding is becoming more popular. A prerequisite for crossbreeding to be beneficial on a long-term basis is that genetic gain within the parental breeds not be reduced. As long as the crossbred cow population constitutes less than 50\% of the whole population, and young bulls can be tested through crossbred offspring, this prerequisite can be fulfilled. Crossbreeding can increase dairy income substantially, especially in management systems requiring a high level of functional traits.

Key words: crossbreeding, heterosis, dairy production, breeding strategy

\section{INTRODUCTION}

Dairy cattle breeding has improved markedly during the last century. Initially based on phenotypic selec-

Received April 15, 2008.

Accepted June 19, 2008.

${ }^{1}$ Corresponding author: morten.kargo@agrsci.dk tion and few measurements, it now includes optimized breeding schemes based on intense bull dam selection, systematic progeny testing of bulls, and large amounts of data. As a result, genetic gain has increased considerably. In most western countries, the breeding goal has changed in recent years from being primarily focused on milk production and conformation to be much broader, including functional traits such as fertility, health, calving ease, and longevity. The reason for this change is mainly the observed deterioration of functional traits, which results from the high selection pressure on production traits and the antagonistic genetic correlations between functional and production traits (Rauw et al., 1998; Mark, 2004; Miglior et al., 2005). At the same time, the rate of inbreeding has increased within most breeds (Sørensen et al., 2005). Crossbreeding may help to overcome these problems.

Crossbreeding is the mating of individuals from different lines, breeds, or populations. There are 2 main reasons for applying crossbreeding within livestock. The first is to utilize the different additive genetic levels between breeds to generate offspring with better economic ability caused by new combinations of additive genetic components. Utilization of the different additive genetic levels between breeds is termed "specific combining abilities" (Falconer and Mackey, 1996). Second, crosses between pure lines/breeds express heterosis. Crossbred animals are more robust and economically efficient compared with the parental breeds (e.g., Christensen and Pedersen, 1988; MäkiTanila, 2007). Crossbreeding is appealing to many livestock producers and has been recommended by Hansen (2000) and Kalm (2002). Crossbreeding has been used extensively in beef cattle, pig, and poultry production systems in the last decades with great success. In contrast, crossbreeding has not been widely used for dairy cattle breeding in developed countries except in New Zealand. One of the major reasons for the restricted use is the low reproductive rate within dairy cattle. With increasing herd size (in Denmark the herd size has doubled up to 120 cows within the last 10 yr; Danish Cattle Federation, 2008) and less time spent on each animal, there is a need for robust 
animals that are more or less capable of taking care of themselves. Therefore, there is a growing interest in crossbreeding within dairy production in Denmark and other developed countries (e.g., Laursen, 2005; Heins, 2007; Sørensen, 2007).

Crossbreeding can improve profit for most dairy producers if breeds with approximately the same genetic level for total merit are used. The heterosis obtained from crossbreeding is an added bonus on top of the genetic gain that can be created by pure breeding. The size of the bonus depends on the number and types of breeds involved in the breeding program. Most studies report at least a $10 \%$ increase in total economic gain per cow among $\mathrm{F}_{1}$ crosses between "unrelated" breeds (e.g., Christensen and Pedersen, 1988; Touchberry, 1992; McAllister et al., 1994).

This paper gives the background and prerequisite for crossbreeding programs and demonstrates why crossbreeding is appropriate in dairy farming today. There will be a short description of crossbreeding and a review on heterosis parameters, with emphasis on functional traits. Additionally, results published in Danish from a large crossbreeding experiment carried out in Denmark from 1972 to 1985 will be presented. Relevant crossbreeding schemes to be applied in dairy farming in Denmark and other developed countries will be discussed, including a validation of breeds to be used. Finally, results from a survey carried out in 2005 investigating the attitude toward crossbreeding among Danish dairy farmers will be presented.

\section{CROSSBREEDING AS A PART OF SUSTAINABLE BREEDING}

An important issue in breeding schemes today is sustainability, which involves consideration of proper definition of breeding goals, rate of inbreeding, and genetic variation. Definition of breeding goals involves weighting each trait according to the desired direction and speed of genetic improvement. For more than 25 yr, the breeding goal in the Nordic countries of Finland, Sweden, Norway, and Denmark has included both production and functional traits (e.g., Philipsson et al., 1975; Gjøl-Christensen, 1984; Juga et al., 1999, Pedersen et al., 2003). Nevertheless, the genetic level for several functional traits has been reduced in some dairy breeds in the Nordic countries because of importation of sires from populations giving considerably less weight on these traits. The negative genetic trend for functional traits has a negative influence on cow welfare and on economic returns because farmers are unable to compensate adequately for the decreased genetic level of these traits with improved management. Therefore, definition of a sustainable breeding goal is very important for mainstream breeds. In addition to the economic component, a sustainable breeding goal should include an animal welfare component. Considerations about animal welfare are not based solely on ethical considerations but also on the assumption that consumers in the future will pay more attention to animal welfare issues related to dairy production (Olesen et al., 2000; Nielsen et al., 2006). Products from breeds selected using sustainable breeding goals may become more desirable to the consumer than products from other types of cattle.

Given that separate dairy breeds can fulfill the requirements for efficient breeding programs with acceptable genetic gain, it is beneficial to have several competitive mainstream dairy breeds. By doing so, genetic variation is improved within the whole dairy population, possibilities for adapting dairy production to future production circumstances are optimized (Woolliams and Toro, 2007), and the number of breeds for crossbreeding programs is increased.

Another important issue related to dairy cattle breeding is inbreeding, which may lead to inbreeding depression, reduced genetic variation, and greater frequencies of recessive lethal diseases (Kristensen and Sørensen, 2005). The breeding programs for dairy breeds have been successful in improving production, but at the cost of increased rates of inbreeding. In 2003, the level of inbreeding in Danish Holstein calves was 3.9\% (Sørensen et al., 2005). This number is slightly lower than corresponding estimates for US Holsteins (VanRaden, 2005). For dairy cattle, inbreeding depression has been reported for both production traits (Miglior et al., 1995) and functional traits (Smith et al., 1998; Sørensen et al., 2006). For recessive lethal diseases such as bovine leukocyte adhesion deficiency (BLAD) and complex vertebral malformation (CVM) in Holsteins, inbreeding increases the negative consequences of these diseases at the population level. Furthermore, inbreeding results in reduced genetic gain due to reduced genetic variation. Simulation studies show a reduction in genetic gain of $20 \%$ over a 25 -yr period due to reduced genetic variation from increased inbreeding (Sørensen et al., 1999). Therefore, tools for managing the rate of inbreeding are clearly important to dairy cattle breeding (Sørensen et al., 2008).

Crossbreeding may be a way to increase sustainability within dairy cattle breeding. Inbreeding problems within the herd are removed and heterosis has a substantial positive impact on both production and functional traits. Several scientific reports describing the positive influence of heterosis in dairy cattle exist (e.g., Christensen and Pedersen, 1988; Touchberry, 1992; Heins, 2007). Crossbreeding is of particular interest for dairy producers focusing on functional traits, because 
heterosis effects tend to be greater for these traits (e.g., Christensen and Pedersen, 1988; Touchberry, 1992). Efficient breeding programs within the pure lines remain a prerequisite for crossbreeding. If crossbreeding is used at the expense of genetic gain in the pure breeds, the overall economic benefit over time will be negatively affected. Used properly, heterosis can be a bonus on top of the gain from traditional dairy cattle breeding programs.

\section{THE THEORY OF CROSSBREEDING}

Heterosis was first described by Shull in 1914 (Shull, 1948) and is defined as the increased performance of crossbred animals compared with the average of the purebred parental populations. The increased performance is due to changes in nonadditive genetic effects of dominance and epistasis. Thorough discussions on the theory behind crossbreeding in dairy cattle have been given by Swan and Kinghorn (1992). Dominance effects are caused by gene interaction within loci. In general, animals with more heterozygous loci have better performance compared with animals with more homozygous loci. Often, pure breeds have an increased degree of homozygosity due to selection and genetic drift. In crossbred animals, there is a larger chance that genes within loci are heterozygous because the genes at a locus originate from different breeds. If the parental breeds have different alleles or different allele frequencies, the offspring will show greater heterozygosity and heterosis compared with crosses between parental breeds with similar allele frequency. Therefore, in general, heterosis increases with increased genetic distance between the parental breeds (Mäki-Tanila, 2007), and with increased inbreeding in the parental breeds. The greater the chance that 2 genes within a locus originate from different breeds, the more heterosis is obtained. Heterosis due to dominance effects is therefore fully expressed in first-generation crosses $\left(\mathrm{F}_{1}\right)$, where all pairs of genes have one gene from each of the breeds.

The degree of heterosis for a specific breed combination expressed in an animal is equal to the chance that the animal, at a specific locus, has one gene from each of the breeds. This is called breed heterozygosity and can be calculated as follows:

$$
\begin{gathered}
\text { Breed heterozygosity }=\operatorname{sbp}_{(\text {breed1) }} \times \operatorname{dbp}_{(\text {breed2) }} \\
+\operatorname{sbp}_{(\text {breed2) }} \times \operatorname{dbp}_{(\text {breed } 1)}
\end{gathered}
$$

where sbp is the breed proportion of a given sire breed and dbp is the breed proportion of the dam.
Epistatic effects are caused by gene interaction between loci. Although interaction between single genes is most important, interactions between gene pairs and between single genes and gene pairs may have an influence. Under both natural and artificial selection, co-adapted positive gene complexes accumulate. However, favorable gene combinations established in the parental breeds may be lost by crossbreeding for traits that have been under selection. This effect is called recombination loss. Consequently, the magnitude of heterosis in crossbred populations should not be predicted solely from $\mathrm{F}_{1}$ heterosis and the retained degree of heterozygosity. Different models for estimating effects of recombination caused by additive $\times$ additive $(\mathbf{A} \times \mathbf{A})$ interaction have been proposed (Dickerson, 1973; Kinghorn, 1980; Hill, 1982). The models were compared (Christensen and Pedersen, 1988) and it was concluded that the models resulted in identical determination, and that the genetic effects estimated by the models were functions of each other. The observed $\mathrm{F}_{1}$ heterosis is therefore the sum of the dominance effects (normally positive) and the epistatic effects (often negative), with dominance effects usually the largest part by far.

Heterosis can be interpreted as inbreeding depression in reverse (Lynch and Walsh, 1998). Heterosis, like inbreeding depression, is most pronounced for traits related to fitness (Kristensen and Sørensen, 2005; Mäki-Tanila, 2007); for example, fertility, calving ease, and robustness. In general, most traits important for profitability within dairy farming show heterosis.

Under the assumption of the dominance model (where epistatic effects are neglected), $\mathrm{F}_{1}$ heterosis is anticipated to be the dominance effect. If $2 \mathrm{~F}_{1}$ animals are crossed, only half of the $\mathrm{F}_{1}$ heterosis is expressed in the offspring $\left(\mathrm{F}_{2}\right)$. With continued crossing between 2 breeds, $67 \%$ of the $\mathrm{F}_{1}$ heterosis will, on average, be expressed. If a 3-breed rotational crossbreeding system is applied, $86 \%$ of the $\mathrm{F}_{1}$ heterosis will be retained assuming that the sires always belong to the purebred parental breeds.

Before suggesting crossbreeding between 2 or 3 specific dairy breeds, it should be determined whether the expression seen in the $\mathrm{F}_{1}$ offspring is due to the additive genetic level of the included breeds or due to dominance effects. If possible, the influence of epistatic effects should also be investigated. However, it is often difficult to find updated breed-specific estimates for the level of these components.

\section{HETEROSIS PARAMETERS}

Before deciding whether crossbreeding is advisable, the expected heterosis effects must be known. For that 
Table 1. Number of calvings in the Danish experiment distributed by year of calving and breed combination of dams

\begin{tabular}{|c|c|c|c|c|c|c|}
\hline Year & Finnish Ayrshire & Danish Red & Holstein-Friesian & \multicolumn{2}{|c|}{ Crossbreds } & Total \\
\hline 1972 & 17 & 143 & 14 & 0 & 0 & 184 \\
\hline 1974 & 25 & 307 & 26 & 0 & 0 & 358 \\
\hline 1975 & 23 & 269 & 25 & 29 & 0 & 346 \\
\hline 1976 & 23 & 196 & 26 & 74 & 0 & 319 \\
\hline 1979 & 22 & 29 & 26 & 192 & 91 & 360 \\
\hline 1980 & 23 & 18 & 27 & 139 & 156 & 363 \\
\hline 1981 & 18 & 10 & 32 & 98 & 206 & 364 \\
\hline 1982 & 26 & 9 & 41 & 51 & 255 & 382 \\
\hline 1983 & 21 & 7 & 43 & 31 & 263 & 365 \\
\hline 1984 & 22 & 9 & 43 & 13 & 280 & 367 \\
\hline All & 299 & 1,485 & 386 & 1,009 & 1,292 & 4,471 \\
\hline
\end{tabular}

purpose, this review based on relevant Danish and international literature has been undertaken. The heterosis estimates originate from both designed experiments and field data. As early as 1906, a crossbreeding experiment with more than 400 cows was carried out in Denmark using Danish Red and Jersey cattle (Robertson, 1949). Large experiments have also been carried out in the United States. Among these are the experiments from Beltsville, Maryland, with crosses between Brown Swiss, Ayrshire, and Holstein (McDowell and McDaniel, 1968) and in Illinois with crosses between Guernsey and Holstein (Touchberry, 1992). Valuable experiments and field studies have also taken place in Germany (Freyer et al., 2008). Recently, field studies in California have been undertaken (Heins, 2007) and ongoing experiments are being performed at Moorepark, Ireland (Walsh et al., 2007).

The most important Danish contribution is a crossbreeding experiment at Næsgaard Agricultural School (Stubbekøbing, Denmark) conducted between 1972 and 1985. Heterosis estimates for production traits have been published internationally (Pedersen and Christensen, 1989), but estimates for functional traits have only been published in Danish (Christensen and Pedersen, 1988). Because this experiment contributes to a substantial part of the heterosis estimates for functional traits, the design of the experiment will be briefly described.

\section{The Danish Crossbreeding Experiment}

The purpose of the Danish experiment was to examine the benefits of systematic crossing of the following unrelated dairy breeds: Finnish Ayrshire (FA), Danish Red (DR), and Holstein Friesian (HF). Hereafter, this experiment will be referred to as "the Danish experiment." The experiment included 319 to 382 calvings and succeeding lactations per year and the female offspring from these calvings during the period from 1972 to 1985. All animals were kept at Næsgaard Agricultural School. Besides purebred lines, 2- and 3-breed crossbred groups were established using selected sires of the 3 breeds. The breed combinations of the dams within the different years are given in Table 1. Throughout the experiment, the pure breeds were maintained in balance with the different crossbred groups. In total, $49 \mathrm{AI}$ sires (16 FA, $17 \mathrm{DR}$, and $16 \mathrm{HF}$ ) and 1,680 cows with 4,471 calvings were included in the experiment.

The experimental design was constructed such that epistatic effects could be included when analyzing data from the experiment. Because $\mathrm{A} \times \mathrm{A}$ interaction is the most important type of epistatic effect when dealing with traits under selection (e.g., milk yield in dairy cows), only $\mathrm{A} \times \mathrm{A}$ epistatic effects were included in the models. Data were analyzed using 3 different animal models: a dominance model, a recombination model (including both dominance and $\mathrm{A} \times \mathrm{A}$ interaction), and a model in which the different purebred and crossbred groups were included as fixed effects. Dominance and epistatic effects were included as fixed effects. For most traits, the recombination model was superior to the dominance model in predicting the observed results of the crossbred groups. For stillbirth and calving difficulties, maternal genetic effects were included in the model. A thorough description of the experimental design and the models used can be found in Pedersen and Christensen (1989).

Results for the average $F_{1}$ heterosis obtained by crossing FA, DR, and HF are given based on estimates using a dominance model (model 1), whereas results for the heterosis obtained by continued 3-breed rotational crossing are based on a recombination model (model 2). The presented heterosis estimates in Tables 3, 4, 5,7 , and 8 are measured in the trait units given in the 
Table 2. Heterosis (in percentage) for fat and protein based on field data

\begin{tabular}{lclcll}
\hline \multicolumn{2}{c}{ Heterosis } & & & & \\
\cline { 1 - 2 } Fat & Protein & & Breed & & \\
& Animals, n & Country $^{2}$ & Reference \\
\hline 4.4 & 4.1 & Across breeds & 150,000 & US & VanRaden and Sanders (2003) \\
8.4 & 8.2 & DR $\times$ BS & $1,827,117$ & DK & Sørensen (1992) \\
3.2 & 2.7 & DKF $\times$ DR & & & \\
1.9 & 1.5 & DKF $\times$ HF & & & Van der Werf and de Boer (1989) \\
2.3 & 2.4 & NLF $\times$ HF & 399,383 & NL & Touchberry (1992) \\
8.0 & 7.5 & HF $\times$ GU & - & US & Ericson et al. (1988) \\
1.7 & - & SLB $\times$ SRB & 174,025 & SV & Dechow et al. (2007) \\
$7.3^{3}$ & $5.6^{3}$ & BS $\times$ HF & 3,473 & US & Lopez-Villalobos et al. (2000a) \\
3.8 & 3.9 & HF $\times$ J & - & NZ & \\
2.0 & 2.0 & HF $\times$ AYR & & & \\
4.5 & 4.6 & J $\times$ AYR & & & \\
\hline
\end{tabular}

${ }^{1}$ DR = Danish Red; BS = Brown Swiss; DKF = Danish Friesian; NLF = Dutch Friesian; GU = Guernsey; SLB = Swedish Friesian; SRB = Swedish Red; AYR = Ayrshire; J = Jersey; HF = Holstein Friesian.

${ }^{2} \mathrm{US}=$ United States; DK = Denmark; NL = the Netherlands; SV = Sweden; NZ = New Zealand.

${ }^{3}$ Estimates from a recombination model.

tables and not in percentage (except when the unit is percentage). For traits measured in percentage (e.g., disease incidence) an $\mathrm{F}_{1}$ animal with a parent average of $30 \%$ for disease incidence and $\mathrm{F}_{1}$ heterosis at $5 \%$ will have a disease incidence at $25 \%$. The recombination effects are positive if the estimates for the heterosis obtained in a continued 3-breed rotational crossing are greater than $86 \%$ of the estimated $\mathrm{F}_{1}$ heterosis using a dominance model.

\section{Heterosis for Milk Production Traits}

Heterosis for fat and protein estimated from field data from several countries is presented in Table 2. The degree of heterosis using a dominance model is in the range from 1.5 to $8.4 \%$. The greatest estimates were found when crossing quite unrelated or inbred breeds; for example, when crossing DR and BS, HF and BS, or HF and Guernsey (Sørensen, 1992; Touchberry, 1992; Dechow et al., 2007). Also, a high level of heterosis was expressed in the Danish experiment, where the breeds included were quite distantly related. Heterosis for milk, fat, and protein were, on average,
6.7, 6.6, and 7.4\%, respectively, estimated with model 1 (Pedersen and Christensen, 1989). However, large negative recombination effects were found for 305-d milk, fat, and protein yields, indicating that much of the $\mathrm{F}_{1}$ heterosis was lost in advanced 2- and 3-breed rotational crossing (Pedersen and Christensen, 1989). Crossing of related breeds, such as Dutch Friesian and HF or Danish Friesian and HF, resulted in relatively small heterosis effects (Van der Werf and de Boer, 1989; Sørensen, 1992). In general, heterosis for fat and protein production estimated on large field data sets using dominance models tended to be smaller than the estimates obtained in the Danish experiment.

\section{Heterosis for Disease Traits}

In general, disease traits show low heritabilities (e.g., Nielsen et al., 1999; Heringstad et al., 2000; Lassen et al., 2003) and therefore substantial heterosis is expected. Table 3 presents estimates of heterosis for disease traits and mortality in the interval from $\mathrm{d} 1$ to 183 of age for heifers from the Danish experiment. All estimates are favorable, and frequencies of enteritis

Table 3. Average frequency for disease treatments and mortality for 2038 calves between 1 and $183 \mathrm{~d}$ of age from the Danish experiment and heterosis (as change in incidence rate) for these traits estimated with a dominance model (model 1) and a recombination model (model 2)

\begin{tabular}{lccc}
\hline Trait & Average & Heterosis (model 1) & Heterosis (model 2) \\
\hline Enteritis, ${ }^{1} \%$ & 12.3 & -8.1 & -9.2 \\
Pneumonia, ${ }^{1} \%$ & 32.1 & -5.2 & -6.5 \\
Other diseases, ${ }^{1} \%$ & 8.3 & -2.7 & -1.9 \\
Mortality, \% & 15.5 & -8.3 & -15.1 \\
\hline
\end{tabular}

${ }^{1}$ Frequency of treatments. 
Table 4. Average frequency for disease treatments of cows (2,756 lactations) measured as number of diseases per 100 lactations from the Danish experiment, and heterosis (as change in incidence rate) for these traits estimated using a dominance model (model 1) and a recombination model (model 2) measured as number of diseases per 100 lactations

\begin{tabular}{lccc}
\hline Trait & Average & Heterosis (model 1) & Heterosis (model 2) \\
\hline Metabolic diseases & 20.5 & $3.5^{1}$ & -3.8 \\
Leg \& claw diseases & 26.2 & -6.2 & -6.1 \\
Reproduction diseases & 38.4 & -2.2 & -0.1 \\
Mastitis & 54.6 & $0.1^{1}$ & $20.6^{1}$ \\
Other diseases & 18.8 & -1.0 & $0.7^{1}$ \\
\hline
\end{tabular}

${ }^{1}$ Positive estimates for heterosis are unfavorable.

and mortality were more than halved for the crossbred animals. For all traits except for that labeled "other diseases," positive recombination effects were found. In the remaining part of the rearing period (from d 183 up to calving) disease incidence and mortality were low, and the heterosis effects for these traits were nearly zero.

Heterosis estimates for diseases in dairy cows from the Danish experiment are given in Table 4. Diseases were recorded as number of diseases (average over all lactations) per 100 lactations. Altogether, there were 159 registered diseases per 100 lactations. The present Danish level is 1.09 veterinary treatments recorded per cow per year (Danish Cattle Federation, 2008).

In general, the recombination model fitted the data better than the dominance model, especially for later crossbred generations, in which more breed combinations appeared. However, the dominance effects and the epistatic effects were difficult to distinguish due to confounding, which is often the case with low heritability traits. For metabolic diseases and leg and claw diseases, significant favorable heterosis estimates were found using a recombination model. In contrast, large unfavorable heterosis estimates were found for mastitis. This unfavorable effect may be an artifact of the model. First, a repeatability model was used, which did not account for unequal distributions of number of lactations among purebred and crossbred cows, with crossbred cows having greater frequency of later lactations. The average number of mastitis outbreaks was
0.797 in third and later lactations compared with 0.341 for first-lactation cows. Second, no correction for yield was made, which will disfavor the high-yielding crossbred cows because of the negative correlations between yield and mastitis. Even though the estimates were unexpected, they were in agreement with unfavorable heterosis estimates for SCS given by VanRaden and Sanders (2003). In general, more heterosis was found for diseases in young calves compared with lactating cows. This result is in agreement with basic theory stating that the greatest heterosis estimates are found for survival traits.

\section{Heterosis for Female Fertility}

Heterosis estimates for fertility were calculated separately for heifers and cows because of differences in their physiologic states (Table 5). The traits "pregnant at first insemination" and "numbers of inseminations per pregnancy" reflect the pregnancy rate, whereas "days from calving to first insemination" reflects the ability to resume cyclicity and express estrus. The trait "days from first insemination to pregnancy" reflects both pregnancy rate and the ability to cycle and express estrus. In the Danish experiment, little heterosis was found for both heifers and cows for traits only related to pregnancy rate. This result is in disagreement with those found by others (Harris et al., 2000; Harris and Kolver, 2001), who estimated substantial heterosis for pregnancy rate (Table 6). For traits reflecting both

Table 5. Average phenotypic level and heterosis estimates for heifer and cow fertility from the Danish experiment estimated using a dominance model (model 1) and a recombination model (model 2) ${ }^{1}$

\begin{tabular}{|c|c|c|c|c|c|c|c|c|}
\hline Trait & \multicolumn{4}{|c|}{ Heifers } & \multicolumn{4}{|c|}{ Cows } \\
\hline Pregnant at first ins., \% & 1,447 & 50.4 & 4.1 & $-1.6^{2}$ & 2,503 & 45.7 & $-0.4^{2}$ & $-1.5^{2}$ \\
\hline Days from first ins. to pregnancy & 1,446 & 36.2 & -5.8 & -1.2 & 2,547 & 48.2 & -11.1 & -9.2 \\
\hline Days from calving to first ins. & - & - & - & - & 2,815 & 72.5 & -1.4 & -2.1 \\
\hline
\end{tabular}

${ }^{1}$ Obs. = observations; ins. = insemination.

${ }^{2}$ Unfavorable heterosis. 
Table 6. Heterosis for fertility

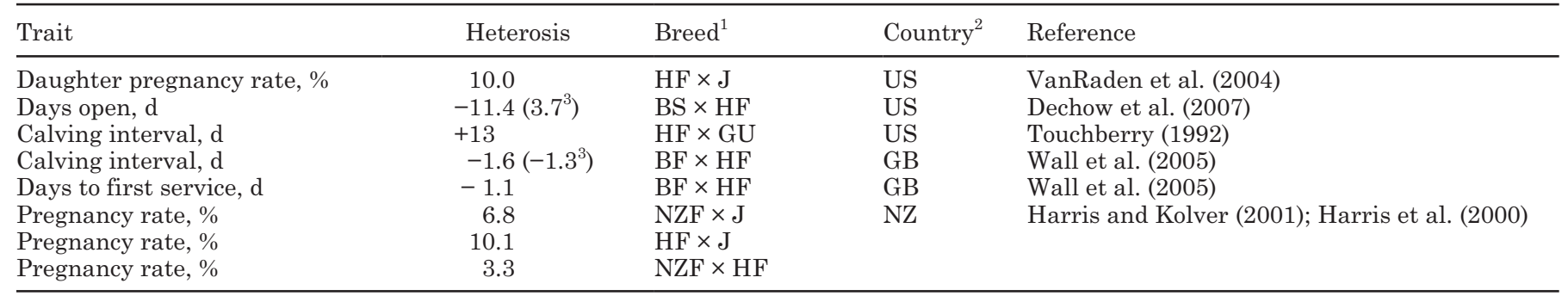

${ }^{1} \mathrm{BS}=$ Brown Swiss; BF = British Friesian; DKF = Danish Friesian; NLF = Dutch Friesian; J = Jersey; HF = Holstein Friesian.

${ }^{2} \mathrm{US}=$ United States; GB = Great Britain; NZ = New Zealand.

${ }^{3}$ Recombination loss.

pregnancy rate and ability to cycle and express estrus, large heterosis estimates were found in the Danish experiment. For cows, the reduction in interval from first insemination to pregnancy was 19.1 and $23.0 \%$, dependent on the model used. This reduction is larger than recent estimates found for the traits (VanRaden et al., 2004; Wall et al., 2005; Dechow et al., 2007), but in the same direction. Contrarily, in the older Illinois experiment, quite large and unfavorable estimates were found for calving interval (Touchberry, 1992).

\section{Heterosis for Calving Ease and Stillbirth}

In the Danish experiment, calving ease was scored on a scale from 1 to 5 , where $1=$ very easy, $2=$ relatively easy, $3=$ difficult, $4=$ very difficult, and $5=$ caesarean. In the analyses, the trait was treated as a categorical trait, with 1 and 2 categorized as normal and 3 to 5 categorized as difficult. Direct and maternal genetic effects on the calving traits were included in the model. The direct genetic effects are due to the genes of the calf, whereas the maternal genetic effects are due to the genes of the cow. Because it was impossible to distinguish between maternal and recombination effects, recombination effects could not be included in the model. Because of quite large differences in frequency of stillbirth and calving difficulties between first and later calvings, calving traits in first and later lactations were treated as different traits. The average frequency of difficult calvings was 10.8 and $2.9 \%$ for primi- and multiparous cows, respectively. For stillbirth, the corresponding figures were 8.0 and $4.4 \%$. These values are slightly lower than stillbirth rates today, which for Holsteins were reported to be 14.0 and $3.7 \%$ for primiand multiparous cows in California (Heins et al., 2006a) and 11.2 and $5.9 \%$ for Danish Holsteins (Danish Cattle Federation, 2008).

Substantial unfavorable heterosis was found for direct effect on both calving ease and stillbirth in heifers (Table 7). This is in accordance with results of Hansen et al. (2004), who estimated the $\mathrm{F}_{1}$ heterosis for direct effects on calving ease and stillbirth to be 13 and 4\%, respectively, for crosses between Danish Friesian and Holstein Friesian. These unfavorable effects were not confirmed in the crossbreeding experiment carried out in California (Heins et al., 2006a). In that experiment, Holstein heifers bred to Normande, Montbeliarde, and Scandinavian Red performed favorably for calving ease and stillbirth compared with Holstein heifers bred to Holstein bulls. However, this difference is due to both heterosis and the more favorable additive genetic level for the traits in the non-Holstein breeds. Because of the experimental design in California, the additive genetic effects and the heterosis effects could not be distinguished. For later calvings, the direct heterosis effect was slightly unfavorable for calving ease and slightly favorable for stillbirth.

Table 7. Average phenotypic level for calving traits of heifers (1,301 observations) and cows (1,631 observations) from the Danish experiment and heterosis estimates

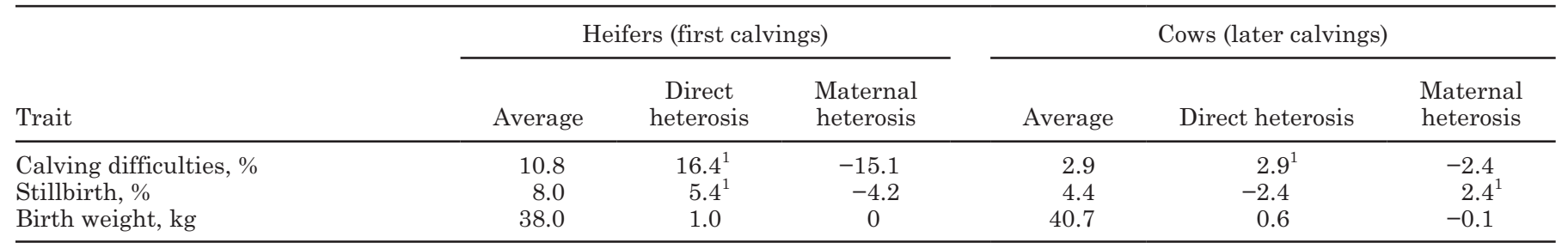

${ }^{1}$ Unfavorable heterosis. 
Table 8. Average survival and heterosis (measured as survival \% or days survived in a given period) of cows from the Danish experiment estimated using a dominance model (model 1) and a recombination model (model 2)

\begin{tabular}{lcccc}
\hline Trait & Obs., n & Average & Model 1 & Model 2 \\
\hline Survived after 1 yr, \% & 1,185 & 82.7 & 4.2 & 12.7 \\
Survived after 2 yr, \% & 1,035 & 51.9 & 18.0 & 21.8 \\
Survived after 3 yr, \% & 870 & 30.7 & 9.5 & 17.0 \\
Days survived, 1 yr & 1,185 & 337 & 7 & 16 \\
Days survived, 2 yr & 1,035 & 587 & 53 & 130 \\
Days survived, 3 yr & 870 & 766 & 122 & 224 \\
\hline
\end{tabular}

Crossbred heifers (maternal effect) had generally very easy calvings and a low rate of stillbirth. This finding is in agreement with Hansen et al. (2004) and Heins et al. (2006a). For cows, the general level of calving difficulties and stillbirth as well as the crossbreeding effects were lower. For calving difficulties, favorable maternal effects were found. In contrast, unfavorable maternal heterosis was found for stillbirth. Both maternal and direct heterosis estimates were low for birth weight, both for heifers and cows.

\section{Heterosis for Longevity}

Longevity of dairy cattle is a trait composed of many different factors that accumulate over time. In the Danish experiment, several records of longevity were recorded. Frequencies of survived cows as well as the average number of days survived (to slaughter, death, or to the end of the period considered) is given in Table 8 . Almost $52 \%$ of the cows survived up to 2 yr after first calving, and $\mathrm{F}_{1}$ heterosis within the period was estimated as $18 \%$ using a dominance model, meaning that $\mathrm{F}_{1}$ crosses had an $18 \%$ greater survival rate compared with the parental average. The estimated effects were greater using the recombination model compared with the dominance model, and therefore, there is no recombination loss for longevity, but rather a recombination gain. This means that heterosis for longevity will stay at a high level, even with continued crossing. Hetero- sis for survival up to a given period after first calving increased with increasing length of the period. This finding is in agreement with results from New Zealand (Harris et al., 2000), where heterosis for survival from first to fifth lactation was more than twice as high as survival from first to second lactation for all breed combinations (Table 9). However, $\mathrm{F}_{1}$ heterosis for longevity estimated with a dominance model (model 1) was quite dependent on the breed combination. Overall, $\mathrm{F}_{1}$ heterosis for crosses between FA and DR was always less favorable than the general $\mathrm{F}_{1}$ heterosis, and the $\mathrm{F}_{1}$ heterosis for crosses between DR and HF and between FA and HF was always more favorable than the general $\mathrm{F}_{1}$ heterosis.

In general, estimates from New Zealand (Harris et al., 2000; Garrick, 2002) are at the same high level as the Danish estimates. VanRaden and Sanders (2003) reported a much smaller estimate for heterosis for longevity, primarily based on crosses between Holstein and Jersey in the United States. The heterosis parameters given by VanRaden and Sanders (2003) were, however, much smaller than earlier estimates from the United States (Hocking et al., 1988; Touchberry, 1992). Furthermore, new results from the United States show that $F_{1}$ crosses have a greater survival rate compared with pure Holstein cows (Heins et al., 2006b). In an economic context, heterosis for longevity is significant. Based on the reviewed material, a general estimate for overall $\mathrm{F}_{1}$ heterosis for longevity is 10 to $15 \%$.

Table 9. Heterosis estimates for longevity

\begin{tabular}{|c|c|c|c|c|}
\hline Trait & Heterosis & Breed $^{1}$ & Country $^{2}$ & Reference \\
\hline Productive life, $\mathrm{d}$ & $\begin{array}{r}222 \\
93 \\
201\end{array}$ & $\begin{array}{l}\mathrm{HF} \times \mathrm{J} \\
\mathrm{HF} \times \mathrm{AYR} \\
\mathrm{J} \times \mathrm{AYR}\end{array}$ & $\mathrm{NZ}$ & Garrick (2002) \\
\hline $\begin{array}{l}\text { Survival from first to second lactation, \% } \\
\text { Survival from first to fifth lactation, \% }\end{array}$ & $\begin{array}{r}3.4 \\
8.8 \\
2.7 \\
9.6 \\
18.3 \\
6.3\end{array}$ & $\begin{array}{l}\mathrm{NZF} \times \mathrm{J} \\
\mathrm{HF} \times \mathrm{J} \\
\mathrm{NZF} \times \mathrm{HF} \\
\mathrm{NZF} \times \mathrm{J} \\
\mathrm{HF} \times \mathrm{J} \\
\mathrm{NZF} \times \mathrm{HF}\end{array}$ & $\mathrm{NZ}$ & Harris et al. (2000) \\
\hline
\end{tabular}

${ }^{1} \mathrm{NZF}=$ New Zealand Friesian; AYR = Ayrshire; J = Jersey; HF = Holstein-Friesian.

${ }^{2}$ US = United States; NZ = New Zealand. 
Table 10. Heterosis estimates for total economic merit

\begin{tabular}{lclll}
\hline Trait & Heterosis, $\%$ & Breed $^{1}$ & Country $^{2}$ & Reference \\
\hline Income per cow per year & 11.4 & HF $\times$ GU & US & Touchberry (1992) \\
Lifetime income & 20.4 & & CND & McAllister et al. (1994) \\
Income per cow & $20^{3}$ & HF, AYR, J & NZ & Lopez-Villalobos et al. (2000a) \\
\hline
\end{tabular}

${ }^{1} \mathrm{HF}=$ Holstein-Friesian; GU = Guernsey; AYR = Ayrshire; $\mathrm{J}=$ Jersey.

${ }^{2} \mathrm{US}=$ United States; CND = Canada $; \mathrm{NZ}=$ New Zealand.

${ }^{3}$ Simulated results.

\section{Heterosis for Economic Merit}

The $\mathrm{F}_{1}$ heterosis for total economic merit of young stock (expressed per live-born female calf from birth to first calving or death in the rearing period) was 9.9\% in the Danish experiment estimated using the dominance model. The observed heterosis by 3 -breed rotational crossing estimated using the recombination model was $19.4 \%$. The economic "merit" was calculated as the value of the heifer before calving minus costs for veterinary treatments, inseminations, and the value of the newborn calf.

The total merit for cows was expressed per cow in a 3 -yr period from first calving. The economic merit per first-lactation cow entering the herd was calculated as income from milk sale, the value of live-born calves, and the slaughter value (if slaughtered in the period) or the value of the cow at the end of the 3 -yr period minus feeding costs, costs related to diseases and calving difficulties, insemination, and the value of the heifer before calving. The $\mathrm{F}_{1}$ heterosis and the obtained heterosis by 3 -breed rotational crossing was 21.2 and $30.4 \%$, respectively. The estimates of heterosis for total merit were only slightly dependent on the assumed prices for milk, feed, and veterinarian treatments.

A major part of the heterosis for total merit was due to improved longevity and increased survival of crossbreds. The high survival rate among crossbred cows could be explained not just by favorable heterosis for yield, reproduction, and diseases, but rather by a general superiority in robustness. Furthermore, heterosis for total economic merit is often caused by multiplicability. This means that, for example, $5 \%$ heterosis for 3 traits of economic importance will often result in greater heterosis for total economic merit. Heterosis for economic merit reported in other studies is presented in Table 10. Touchberry (1992) estimated heterosis for income per cow per year to be $11.4 \%$, McAllister et al. (1994) estimated heterosis for lifetime income to be 20.4\%, and Lopez-Villalobos et al. (2000a) simulated the heterosis for income per cow to be $20 \%$. They are very much in agreement with the results from the Danish experiment. It can be concluded that crossbreeding of dairy cattle breeds results in considerable heterosis for economic merit, with an estimate for the $\mathrm{F}_{1}$ heterosis of at least $10 \%$.

Based on the reviewed literature, expected levels of heterosis for yield and functional traits to be obtained in practice are summarized in Table 11. It is important to recognize that these estimates are general and will vary depending on which breeds are to be crossed. They give a rough prediction of the outcome of crossbreeding programs, when heterosis estimates for the breeds considered in the program are not available. Another issue to take into consideration is that heterosis between 2 breeds might be expressed differently in different environments. Evidence for heterosis by environment interaction for production traits have been shown in New Zealand (Bryant et al., 2007). Heterosis was expressed most for fitness and functional traits, with the exception of direct effects for calving ease, stillbirth, and mastitis. Heterosis for yield traits was approximately $3 \%$, whereas heterosis for most functional traits was in the range from 5 to $15 \%$. Based on the results from the Danish experiment, there is no evidence of recombination loss for functional traits, longevity, and total merit. However, mastitis in lactating cows was an exception. In general, the issue of recombination loss and epistatic effects ought to be an important theme in upcoming crossbreeding experiments.

\section{OPTIMAL CROSSBREEDING STRATEGIES}

For crossbreeding to be profitable, systematic breeding strategies have to be followed consistently, and breeds should be used that, to a certain degree, are

Table 11. Guidelines for Danish dairy producers on expected $\mathrm{F}_{1}$ heterosis to be obtained for important traits

\begin{tabular}{ll}
\hline Trait & $\begin{array}{l}\text { Expected } \\
\text { heterosis, \% }\end{array}$ \\
\hline Production traits & $\sim 3$ \\
Fertility & $\sim 10$ \\
Calving ease (direct) & -10 to 15 \\
Stillbirth (direct) & -5 to 10 \\
Calving ease (maternal) & 10 to 15 \\
Stillbirth (maternal) & 5 to 10 \\
Longevity & 10 to 15 \\
Total merit & $\geq 10$ \\
\hline
\end{tabular}


equal with respect to total merit. Under the assumption of the dominance model, $67 \%$ of the $\mathrm{F}_{1}$ heterosis is maintained under a 2 -breed rotational crossing program. When using a 3-breed rotational crossing, the maintained heterosis increased up to $86 \%$ of $\mathrm{F}_{1}$ heterosis. Therefore, the third breed can deviate slightly from the requirement laid out above. Inclusion of a fourth breed in the rotational crossing program only increased the maintained heterosis to $93 \%$ of $\mathrm{F}_{1}$ heterosis. It would, therefore, be economically beneficial to include a fourth breed in the crossbreeding program only if the breed were at the same genetic level for total merit as the 3 breeds already chosen for the program.

Another way to exploit heterosis in a commercial herd is to use terminal $\mathrm{F}_{1}$ production animals. The low reproduction rate within dairy cattle has been a limitation to this approach, but the availability of sexed semen may create new possibilities. If crossbreeding and sexed semen are combined, production herds can have a nucleus of purebred cows sired by sexed semen to produce replacements for the nucleus and $F_{1}$ production cows. Offspring from the $\mathrm{F}_{1}$ production cows will only be used for meat production, and these animals can be inseminated with beef semen to increase the value of their offspring as beef animals. There is, however, a need for optimization of breeding strategies that combine use of sexed semen with crossbreeding.

The requirements for the chosen breeds and how they complement each other have to be considered when planning crossbreeding systems. By using breeds for crossbreeding with greater genetic levels for traits of importance than the present breed(s), rapid improvement for these traits will be obtained. For example, Jerseys will contribute with a greater genetic level for milk components when crossed with Holstein. Unless one of the breeds to be included in a program can contribute with an outstanding performance (e.g., resistance to certain diseases), more or less economically equal breeds must be used for crossbreeding programs. In this respect, the Nordic Red breeds are a good combination with Holsteins. A recent Swedish investigation, based on economic information from dairy herds, has shown that total profit for Swedish Red and Swedish Holstein is similar, with Swedish Holsteins having a slightly greater income and Swedish Reds having slightly lower costs (Lidfeldt, 2006). This fact is one of the reasons why semen export for sires of the Scandinavian Red breeds has increased. The export of Swedish Red semen, for example, has increased more than 4 -fold within the last $4 \mathrm{yr}$, and now almost 600,000 doses per year are exported.

In Denmark, most dairy producers initiating systematic crossbreeding have herds that are composed of Holstein cows. However, crossbreeding has been initiated in a few Danish Red and Jersey herds. Regardless of the founder population, a 3-breed rotational crossbreeding program is recommended. For Holstein herds, the first breed of sire recommended in a 3-breed rotational program is one of the Nordic Red breeds [Swedish Red (SR), Norwegian Red (NRF), Finnish Ayrshire (FA), and Danish Red (DR)], because they are tested under Nordic production circumstances. To avoid a reduction in the heterosis effect, Nordic Red AI bulls with HF genes should be avoided in the crossbreeding program. In Denmark, SR sires are often used for crossbreeding with Holstein females, as well as DR sires with little or no contribution from Holstein ancestors. As a third breed, Jersey is an obvious choice for Danish dairy producers, because more than 60 Jersey young bulls are progeny tested in Denmark every year. Jersey is heavily used in a 2-breed crossing program in New Zealand, where $30 \%$ of the 3.8 million dairy cows at present are crossbreds (Harris et al., 2007). However, many Danish dairy producers are worried about the variation of cow size and milk content that occur when Jersey is used in a 3-breed rotation; therefore, Montbéliarde is preferred by some over the Jersey breed. Other alternative breeds such as Milking Simmental, Normande, or Brown Swiss could be used. These breeds are not, however, recommended by Danish breeding advisors in general, because adequate documentation for additive genetic level for these breeds compared with Danish breeds is lacking. Another consideration to take when choosing breeds at the herd level is the availability of active bulls from which to choose. The number of bulls can, under certain circumstances, be reduced because of veterinarian or competitive reasons.

Overall, the use of systematic crossbreeding schemes in dairy production tends to be more beneficial as relationships within the pure breeds increase (Hansen, 2000) and as more emphasis is put on functional traits within the dairy herds both in conventional and organic dairy farming. This, in combination with breeds that have had little or negative trends for the functional traits, increases the advantage of crossbreeding including breed(s) with high weight on functional traits. Still, genetic improvement of the pure breeds should not be reduced because of crossing. In particular, the size of progeny-testing programs should not be reduced to pursue crossbreeding. With large numbers of crossbred cows in the population, test capacity could be reduced if crossbred offspring cannot be used for evaluation of test bulls. Methods that include crossbred offspring in the evaluation, such as those presented by Lidauer et al. (2006) and VanRaden and Tooker (2007), should be implemented if systematic crossbreeding becomes routine. Systematic crossbreeding may also reduce genetic gain in the pure breeds due to reduction in 
the number of cows in the population, and thereby a reduction in selection intensity of bull dams will occur. However, as long as the proportion of crossbred cows is less than $50 \%$, this should not be a problem. Calculations from New Zealand have shown that reduction in genetic gain will be $10 \%$ for Jerseys and Holsteins in a systematic 3-breed crossbreeding program including Holstein, Jersey, and Ayrshire compared with the present gain if $90 \%$ of the New Zealand dairy producers turn to crossbreeding (Lopez-Villalobos et al., 2000b). For Ayrshires, an extra genetic gain of $10 \%$ is obtained because more bulls are progeny-tested than in the present situation. If new technologies such as genomic selection become important contributors to dairy cattle breeding schemes, the importance of progeny testing and bull dam selection within the whole population will decrease. In that case, the negative side effects of crossbreeding at population level are expected to be lower.

\section{ATTITUDES OF DANISH DAIRY FARMERS TOWARD CROSSBREEDING}

Despite the very positive economic results shown in the Danish experiment in the late 1980s, and despite the popularity of crossbreeding in pig and poultry breeding within Denmark, few Danish dairy farmers initiated systematic crossbreeding programs at that time. In 2004, there was a revitalization of interest in crossbreeding, partly due to the increased focus on functional traits in Denmark and worldwide, but also due to the increased interest in crossbreeding in other countries. Today, approximately 90 of 4,200 to 4,300 Danish dairy herds apply crossbreeding, some for the whole herd and others for parts of the herd.

Because of this interest, a survey was conducted to investigate the attitude toward crossbreeding among Danish dairy farmers (Laursen, 2005). Few surveys such as this have been carried out before and none in Denmark. In the United States, a survey was carried out in the beginning of the current decade (Weigel and Barless, 2003), but the response was quite low: only 50 out of 528 questionnaires were returned. In the Danish survey, 475 questionnaires were sent out (the sample population), which is approximately $10 \%$ of the total number of dairy farms in Denmark. The sample population was selected using a proportional stratification with respect to herd size; 282 dairy farmers (about $60 \%)$ responded to the survey.

In the survey, information on breed, production system, and age of the farmers was collected. Overall, $41 \%$ of the respondents had a positive attitude toward crossbreeding and $35 \%$ had a negative attitude. Some $24 \%$ of the respondents would consider crossbreed- ing in the whole herd as a possibility and $40 \%$ were negative toward crossbreeding in the whole herd; the remainder had not made up their minds. Forty percent viewed crossbreeding favorably for a portion of the herd, whereas $39 \%$ viewed this practice unfavorably. Relationships between the breed of the herd and the attitude toward crossbreeding were found. There was a slightly more positive attitude toward crossbreeding among owners of DR herds, and a slightly more negative view among owners of Jersey herds. Age of the herd owner, herd size, and production system had no significant relationship to attitude toward crossbreeding.

Four of 10 dairy farmers in Denmark had a positive attitude toward crossbreeding, and about 1 in 4 would consider crossbreeding in their herd in the future. Based on that response, a strong increase in the frequency of dairy cows being crossbred in Denmark is expected. As a result, breeding advisors, who today primarily focus on pure breeding, need to change their focus toward crossbreeding.

\section{CONCLUSIONS}

Systematic crossbreeding contributes to a substantial increase in the economic performance of dairy production systems, and this review clearly shows that heterosis exists for the most economically important traits in dairy cattle production. The extra gain obtained is greatest for longevity and functional traits, except for mastitis, and somewhat smaller for milk production. However, $\mathrm{F}_{1}$ crossbred calves tend to have more problems during birth and they have a greater frequency of stillbirth. There seems to be no recombination loss for functional traits and sometimes even a "recombination gain" has been expressed. Optimal crossbreeding strategies in dairy herds require 3 breeds with high genetic level regarding total merit to be used in a systematic rotational crossbreeding program. Heterosis is a bonus on top of the genetic gain obtained in the pure parental breeds and should not be at the expense of genetic improvement of the pure breeds. However, genetic gain in the parental breeds can be kept at the present level if AI bulls can be tested based on crossbred offspring. Many dairy farmers have recognized the value of crossbreeding. An increase in the use of such a breeding strategy could be expected to lead to increased cow welfare and improved economic efficiency in the dairy industry.

\section{REFERENCES}

Bryant, J. R., N. López-Villalobos, J. E. Pryce, C. W. Holmes, D. L. Johnson, and D. J. Garrick. 2007. Short Communication: Effects of environment on the expression of breed and heterosis effects for production traits. J. Dairy Sci. 90:1548-1553. 
Christensen, L. G., and J. Pedersen. 1988. Crossbreeding of Dairy Cattle. 650th report from the National Institute of Animal Science. Landhusholdningsselskabets forlag, København, Denmark. (in Danish with English subtitles and summary)

Danish Cattle Federation. 2008. Danish Cattle, monthly statistics from the milk recording. Online. http://www.lr.dk/kvaeg/ diverse/001flsydktmain.html Accessed March 7, 2008.

Dechow, C. D., G. W. Rogers, J. B. Cooper, M. I. Phelps, and A. L. Mosholder. 2007. Milk, fat, protein, somatic cell score, and days open among Holstein, Brown Swiss, and their crosses. J. Dairy Sci. 90:3542-3549.

Dickerson, G. E. 1973. Inbreeding and heterosis in animals. Pages 54-77 in Proc. Anim. Breed. Genet. Symp. in Honor of J. L. Lush. Am. Soc Anim. Sci., Champaign, IL.

Ericson, K., B. Danell, and J. Rendel. 1988. Crossbreeding effects between two Swedish Dairy Breeds for Production traits. Livest. Prod. Sci. 20:175-192.

Falconer, D. S., and T. F. C. Mackey. 1996. Introduction to Quantitative Genetics. 4th ed. Longman Sci. Tech., Harlow, UK.

Freyer, G., S. König, B. Fischer, U. Bergfeld, and B. G. Cassell. 2008. Invited Review: Crossbreeding in dairy cattle from a German perspective of the past and today. J. Dairy Sci. 91:3725-3742.

Garrick, D. J. 2002. Principles of genetic improvement in dairy herds. Pages 475-593 in Milk Production From Pasture. C.W. Holmes, I. M. Brookes, D. J. Garrick, D.D.S. Mackenzie, T. J. Parkinson, G. F. Wilson, ed. Massey University, Palmerston North, New Zealand.

Gjøl-Christensen, L. 1984. The Danish sire index for total merit. Pages 193-203 in Progeny Testing Methods in Dairy Cattle. Bulletin 183, IDF/EAAP symposium, Prague, Czechoslovakia.

Hansen, L. B. 2000. Symposium: Selection for milk yield. Consequences of selection for milk yield from a geneticist's viewpoint. J. Dairy Sci. 83:1145-1150.

Hansen, M., M. S. Misztal, M. S. Lund, J. Pedersen, and L. G. Christensen. 2004. Undesired phenotypic and genetic trend for stillbirth in Danish Holstein. J. Dairy Sci. 87:1477-1486.

Harris, B., J. Pryce, and B. Montgomerie. 2007. How sustainable are dairy cattle breeding in Oceania? First Int. Tech. Conf. Anim. Genet. Resour. Food Agric., Interlaken, Switzerland. Online. Available http://www.fao.org/ag/AGAinfo/programmes/en/ genetics/documents/Interlaken/sidevent/5_5/Harris.pdf, accessed April 12th, 2008.

Harris, B. L., and E. S. Kolver. 2001. Review of holsteinization on intensive pastoral dairy farming in New Zealand. J. Dairy Sci. 84(E.Suppl.):E56-E61.

Harris, B. L., A. M. Winkelman, and L. J. Burton. 2000. Comparisons of fertility measures in strains of Holstein-Frisian cows, Jersey cows and their crosses. Pages 71-78 in Proc. Massey Dairy Farmer's conference, New Zealand.

Heins, B. J. 2007. Impact of an old technology on profitable dairying in the 21st century. Pages 7-19 in Crossbreeding of Dairy Cattle: The Science and the Impact. 4th Biennial W. E. Petersen Symposium, University of Minnesota, St. Paul. http://www. ansci.umn.edu/petersen_symposium/petersen2007.htm Accessed March 19, 2008.

Heins, B. J., L. B. Hansen, and A. J. Seykora. 2006a. Calving difficulty and stillbirths of pure Holstein versus crossbreds of Holstein with Normande, Montbeliarde, and Scandinavian Red. J. Dairy Sci. 89:2805-2810.

Heins, B. J., L. B. Hansen, and A. J. Seykora. 2006b. Fertility and survival of pure Holsteins versus crossbreds of Holstein with Normande, Montbeliarde, and Scandinavian Red. J. Dairy Sci. 89:4944-4951.

Heringstad, B., G. Klemetsdal, and J. Ruane. 2000. Selection for mastitis resistance in dairy cattle: A review with focus on the situation in the Nordic countries. Livest. Prod. Sci. 64:95-106.

Hill, W. G. 1982. Dominance and epistasis as components of heterosis. Z. Tierzücht. Züchtbiol. 99:161-168.

Hocking, P. M., A. J. McAllister, M. S. Wolynets, T. R. Batra, A. J. Lee, C. Y. Lin, G. L. Roy, J. A. Vesely, J. M. Wauthy, and K.
A. Winter. 1988. Factors affecting length of herdlife in purebred and crossbred dairy cattle. J. Dairy Sci. 71:1011-1024.

Juga, J., E. A. Mäntysaari, and J. Pösö. 1999. Economic response to total merit selection in Finnish Ayrshire breeding. Interbull Bull. 23:79-87.

Kalm, E. 2002. Development of cattle breeding strategies in Europe. Arch. Tierzucht. 45:5-12.

Kinghorn, B. 1980. The expression of "Recombination loss" in quantitative traits. Z. Tierzücht. Züchtbiol. 97:138-143.

Kristensen, T. N., and A. C. Sørensen. 2005. Inbreeding-Lessons from animal breeding, evolutionary biology and conservation genetics. Anim. Sci. 80:121-133.

Lassen, J., M. Hansen, M. K. Sørensen, G. P. Aamand, L. G. Christensen, and P. Madsen. 2003. Genetic relationship between body condition score, dairy character, mastitis, and diseases other than mastitis in first-parity Danish Holstein cows. J. Dairy Sci. 86:3730-3735.

Laursen, M. V. 2005. [Crossbreeding in future dairy farming]. Bachelor project. Faculty of Life Sciences, Copenhagen University, Denmark. (In Danish)

Lidauer, M., E. A. Mäntysaari, I. Stranden, J. Pösö, J. Pedersen, U. S. Nielsen, K. Johansen, J. A. Eriksson, P. Madsen, and G. Aamand. 2006. Random heterosis and recombination loss effects in a multibreed evaluation for Nordic Red dairy cattle. 8th WCGALP, Belo Horizonte, Brazil.

Lidfeldt, M. 2006. [Comparison of economic performance between SRB and SLB]. The Swedish Red Association, Falkenberg, Sweden. (In Swedish)

Lopez-Villalobos, N., D. J. Garrick, H. T. Blair, and C. W. Holmes. $2000 \mathrm{~b}$. Possible effects of 25 years selection and crossbreeding on the genetic merit and productivity of New Zealand dairy cattle. J. Dairy Sci. 83:154-163.

Lopez-Villalobos, N., D. J. Garrick, C. W. Holmes, H. T. Blair, and R. J. Spelman. 2000a. Profitabilities of some mating systems for dairy herds in New Zealand. J. Dairy Sci. 83:144-153.

Lynch, M., and B. Walsh. 1998. Genetics and analysis of quantitative traits. Sinauer Associates, Sunderland, MA.

Mäki-Tanila, A. 2007. An overview on quantitative and genomic tools for utilizing dominance genetic variation in improving animal production. Agric. Food Sci. 16:188-198.

Mark, T. 2004. Applied genetic evaluations for production and functional traits in dairy cattle. J. Dairy Sci. 87:2641-2652.

McAllister, A. J., A. J. Lee, T. R. Batra, C. Y. Lin, G. L. Roy, J. A. Vesely, J. M. Wauthy, and K. A. Winter. 1994. The influence of additive and non additive gene action on lifetime yields and profitability in dairy cattle. J. Dairy Sci. 77:2400-2414.

McDowell, R. E., and B. T. Mc Daniel. 1968. Interbreed matings in dairy cattle. I. yield traits, feed efficiency, type and rate of milking. J. Dairy Sci. 51:767-777.

Miglior, F., E. B. Burnside, and B. W. Kennedy. 1995. Production traits of Holstein cattle: Estimation of nonadditive genetic variance components and inbreeding depression. J. Dairy Sci. 78:1174-1180.

Miglior, F., B. L. Muir, and B. J. Van Doormaal. 2005. Selection indices in Holstein cattle of various countries. J. Dairy Sci. 88:1255-1263.

Nielsen, H. M., L. G. Christensen, and J. Ødegård. 2006. A method to define breeding goals for sustainable dairy cattle production. J. Dairy Sci. 89:3615-3625.

Nielsen, U. S., G. A. Pedersen, J. Pedersen, and J. Jensen. 1999. Genetic variation in disease traits and their relationships with survival in Danish dairy cattle. Interbull Bull. 21:170-177.

Olesen, I., A. F. Groen, and B. Gjerde. 2000. Definition of animal breeding goals for sustainable production systems. J. Anim. Sci. 78:570-582

Pedersen, J., and L. G. Christensen. 1989. Heterosis for milk production traits by crossing Red Danish, Finish Ayrshire and Holstein-Friesian cattle. Livest. Prod. Sci. 23:253-266.

Pedersen, J., U. S. Nielsen, and G. P. Aamand. 2003. S-indeks for tyre af malke- og kombinationsracer, 2002. Report no 104 
Danish Agricultural Centre, Danish Cattle, Skejby, Denmark. (In Danish)

Philipsson, J., L. Jansson, and E. Brännäng. 1975. Selection index of bulls regarding economically important characters. Report of the Agricultural College of Sweden, Uppsala.

Rauw, W. M., E. Kanis, E. N. Noordhuizen, and F. J. Grommers. 1998. Undesirable side effects of selection for high production efficiency in farm animals: A review. Livest. Prod. Sci. 56:1333.

Robertson, A. 1949. Crossbreeding experiments with dairy cattle. Anim. Breed. Abstr. 17:201-208.

Shull, G. H. 1948. What is "heterosis"? Genetics 33:439-446.

Smith, L. A., B. G. Cassell, and R. E. Pearson. 1998. The effects of inbreeding on the lifetime performance of dairy cattle. J. Dairy Sci. 81:2729-2737.

Sørensen, A. C., P. Madsen, M. K. Sørensen, and P. Berg. 2006. Udder health shows inbreeding depression in Danish Holstein. J. Dairy Sci. 89:4077-4082.

Sørensen, A. C., M. K. Sørensen, and P. Berg. 2005. Inbreeding in Danish Dairy Cattle Breeds. J. Dairy Sci. 88:1865-1872.

Sørensen, M. K. 1992. [Estimation of heterosis effects for yield in Danish dairy populations]. MS thesis. The Danish Agricultural University, Copenhagen. (In Danish)

Sørensen, M. K. 2007. Crossbreeding-An important part of sustainable breeding in dairy cattle and possibilities for implementation. Pages 29-40 in Crossbreeding of Dairy Cattle: The Science and the Impact. 4th Biennial W. E. Petersen Symposium, University of Minnesota, St. Paul. http://www. ansci.umn.edu/petersen_symposium/petersen2007.htm Accessed March 19, 2008.

Sørensen, M. K., P. Berg, J. Jensen, and L. G. Christensen. 1999 Stochastic simulation of breeding schemes for total merit in dairy cattle. GIFT Seminar on Genetic Improvement of Functional Traits in Cattle, Wageningen, the Netherlands. Interbull Bull. 23:183-192.

Sørensen, M. K., A. C. Sørensen, R. Baumung, S. Borchersen, and P. Berg. 2008. Optimal genetic contribution selection in Danish Holstein depends on pedigree quality. Livest. Sci. doi:10.1016/j. livsci.2008.01.027
Swan, A. A., and B. P. Kinghorn. 1992. Symposium: Dairy crossbreeding: Evaluation and exploitation of crossbreeding in dairy cattle. J. Dairy Sci. 75:624-639.

Touchberry, R. W. 1992. Crossbreeding effects in dairy cattle: The Illinois experiment, 1949 to 1969. J. Dairy Sci. 75:640-667.

Van der Werf, J. H. J., and W. de Boer. 1989. Estimation of genetic parameters in a crossbred population of Black and White dairy cattle. J. Dairy Sci. 72:2615-2623.

VanRaden, P. M., and A. H. Sanders. 2003. Economic merit of crossbred and purebred US dairy cattle. J. Dairy Sci. 86:10361044.

VanRaden, P. M., and M. E. Tooker. 2007. Genetic evaluations using combined data from all breeds and crossbred cows. Pages 23-28 in Crossbreeding of Dairy Cattle: The Science and the Impact. 4th Biennial W. E. Petersen Symposium, University of Minnesota, St. Paul. http://www.ansci.umn.edu/petersen_symposium/ petersen2007.htm Accessed March 19, 2008.

VanRaden, P. M., M. E. Tooker, and J. B. Cole. 2004. Heterosis and breed differences for daughter pregnancy rate in crossbred cows. J. Dairy Sci. 87(Suppl. 1):284. (Abstr.)

VanRaden, P. M. 2005. Inbreeding adjustments and effects on genetic trend estimates. Interbull Bull. 33:81-84.

Wall, E., S. Brotherstone, J. F. Kearney, J. A. Woolliams, and M. P. Coffey. 2005. Impact of nonadditive effects in the estimation of breeding values for fertility and correlated traits. J. Dairy Sci. 88:376-385.

Walsh, S., F. Buckley, D. P. Berry, M. Rath, K. Pierce, N. Byrne, and P. Dillon. 2007. Effects of breed, feeding system, and parity on udder health and milking characteristics. J. Dairy Sci. 90:57675779

Weigel, K. A., and K. A. Barless. 2003. Results of a producer survey regarding crossbreeding on US dairy farms. J. Dairy Sci. 86:4148-4154.

Woolliams, J., and M. Toro. 2007. What is genetic diversity? Pages 55-74 in Utilization and Conservation of Farm Animal Genetic Resources. K. Oldenbroek, ed. Wageningen Academic Publishers, Wageningen, the Netherlands. 